\title{
Temporal trends in and relationships between screen time, physical activity, overweight and obesity
}

Mitch J Duncan ${ }^{1 *}$, Corneel Vandelanotte ${ }^{1}$, Cristina Caperchione ${ }^{2}$, Christine Hanley ${ }^{1}$ and W Kerry Mummery ${ }^{3}$

\begin{abstract}
Background: The aims of this study were to examine temporal trends in the prevalence of sufficient moderate-to-vigorous intensity physical activity (MVPA), high levels of screen time, combined measures of these behaviors and overweight or obesity in Australian adults during the period 2002-2008. Trends over this time period in overweight or obesity within each behavior group (sufficient/insufficient MVPA, high/low screen time and combined behaviors) were also examined.

Methods: Data were collected via annually conducted cross-sectional computer-assisted-telephone-interviews (CATI) of adults ( $n=7908$ ) living in Central Queensland, Australia (2002-2008). Self-reported MVPA, screen time (TV viewing and computer use), and BMI were used to create dichotomous classifications of physical activity (Sufficient MVPA (S-MVPA), Insufficient Physical Activity (I-MVPA)), screen time (High Screen Time (HST), Low Screen Time (LST)), combined behavior categories (S-MVPA/LST, I-MVPA/LST, S-MVPA/HST, I-MVPA/HST) and BMI (Overweight or Obese, Healthy Weight) respectively.

Results: The prevalence of S-MVPA, HST, and overweight or obesity increased at approximately the same rate over the study period in the overall sample and females $(p \leq 0.05)$. In the overall sample and in females, the prevalence of overweight and obesity increased over the study period in those individuals classified as I-MVPA/HST ( $\mathrm{p} \leq 0.05)$.

Conclusion: Results provide evidence that while the prevalence of S-MVPA appears to be modestly increasing, the proportion of the population engaging in HST and classified as overweight or obese are increasing at approximately the same rate. These observations highlight the need to increase levels of total physical activity (including light intensity physical activity) and decrease sedentary behavior including screen time.
\end{abstract}

Keywords: Temporal trends, Obesity, Screen time, Physical activity, Adults

\section{Background}

The health benefits of physical activity are numerous and well documented particularly in relation to individuals achieving sufficient levels of moderate-to-vigorous intensity physical activity (MVPA), or sufficient MVPA [1]. Sufficient MVPA is frequently defined as achieving 150 minutes of MVPA in 5 or more sessions in the previous week [2]. Though MVPA levels are generally low in the US, Australia and Canada, the population prevalence of individuals engaging in sufficient MVPA has

\footnotetext{
*Correspondence: m.duncan@cqu.edu.au

${ }^{1}$ CQUniversity, Institute for Health and Social Science Research, Centre for Physical Activity Studies, Rockhampton, Bld 18, CQUniversity Australia, Rockhampton, QLD 4702, Australia

Full list of author information is available at the end of the article
}

gradually increased over recent years [3-6], and has occurred during periods when the prevalence of overweight or obesity has also increased [3,7-9]. Yet trends in the prevalence of sufficient MVPA and overweight or obesity are not equal across population groups, with significant differences observed by gender and age $[5,9,10]$. This apparent paradox in the trends of sufficient MVPA and overweight or obesity may due to reductions in levels of total physical activity due to decreased light intensity physical activity and increased sedentary behavior, increased energy intake or a combination of these behaviors $[7,11]$.

Measures of screen based activities performed in seated postures, such as TV viewing and computer use, 
are commonly used indicators of sedentary behavior as the low metabolic cost of these activities is below the energy expenditure threshold used to define sedentary behavior $(<1.5$ METS) [12,13]. Time spent watching TV and using computers are screen based activities which are associated with increased risk of weight gain, overweight and obesity, diabetes, and CVD mortality [14-16]. Furthermore, the associations between increased screen based activity and the negative health outcomes remain present even when adjusted for engagement in MVPA. As such, the time spent engaged in sedentary behavior is emerging as a potentially important and independent risk factor for ill health $[17,18]$.

There is little data on temporal trends in sedentary behaviors when compared to data on trends in MVPA. In occupational settings, physical activity has declined resulting in increased sedentary behavior in workplaces over recent decades $[3,10,19]$. In non-occupational settings sedentary behavior also appears to be increasing. In the US, time spent watching TV increased approximately 36 minutes every decade in the period 1950-2000 [3]; in Australia, average time spent in non-occupational sedentary behavior increased from 894 minutes/2 days in 1997 to 906 minutes/2 days in 2006 [20]. Furthermore comparisons in the trends of sufficient MVPA and engagement in sedentary behavior are infrequently performed within the same population [20], or the observed trends are difficult to interpret due to changes in survey instruments and methodologies [6,10]. Examining changes in both behaviors is useful in understanding how these two behaviors have changed over time in relation to disease outcomes and risk factors such as overweight or obesity.

Therefore the purpose of this study is threefold, firstly, to examine the relationships between screen time, MVPA and combined measures of these behaviors and being classified as overweight or obese in a pooled sample of Australian adults who completed separate cross sectional surveys in the period 2002-2008. Similar associations have been conducted previously [16,21], and are conducted in the current study to establish the associations between activity behaviors and overweight or obesity in the current sample prior to progressing to the other aims of the study. Secondly, the study aimed to examine temporal trends in the prevalence of these behaviors and being classified as overweight or obese during this period. Thirdly, the study sought to examine temporal trends in the prevalence of being classified as overweight or obese during this period within each of the behavior groups examined (sufficient/insufficient MVPA, high/low screen time and combined behaviors). These relationships will also be examined for the overall study population and within the male and female samples separately.

\section{Methods}

\section{Sample}

This study uses data pooled from a series of separate cross-sectional surveys of the adult population living in Central Queensland, Australia. The surveys were conducted annually by the Population Research Laboratory, at CQUniversity during the period 2002 to 2008. The samples sizes for each survey year are provided in Table 1, the overall sample size was 7908. Details on the survey methods are provided elsewhere and each survey was approved by CQUniversity's Human Research Ethics Committee [5]. Briefly, each survey was performed during October and November using computer-assistedtelephone-interviewing (CATI), all respondents were aged 18 years or older (range 18-93 years), and were living in a dwelling contactable by direct-dialed land based telephone. Participants were randomly selected using a two-stage stratified sampling process where households (as phone numbers are linked to households) were selected first and then individuals within households were selected. Potential telephone numbers were drawn from commercially available Electronic White Pages, all duplicate, cellular and business numbers were removed from the sample before each survey commenced. Each year the sample was stratified by gender to reflect the characteristics of the Australian population based on the Census closest to the survey date, however the sample is not intended to be a representative sample of the Australian population. The response rate for the surveys ranged from $39.3 \%$ in 2007 to $62.3 \%$ in 2005 with an average response rate across surveys of $46.9 \%$. Response rates are comparable to those reported in other recently conducted CATI based surveys [22,23], and no information is available on those who did not participate in the survey.

\section{Measures}

All surveys included items that assessed sociodemographic details of respondents including, gender, age, household income, employment status, education and smoking status. Self-reported height and body weight were used to determine BMI and classify participants into healthy weight $(\mathrm{BMI} \leq 24.9)$ and overweight or obese (BMI $\geq 25.0$ ) categories. Using the Active Australia Questionnaire all participants were asked to report the frequency and duration physical activity during recreational and transport walking, moderate and vigorous intensity physical activity in the previous week [24]. This instrument has demonstrated acceptable test-retest reliability and validity [25,26]. Engagement in sufficient MVPA (S-MVPA) was classified as achieving a minimum of 150 minutes of MVPA in at least five sessions in the previous week, participants not satisfying this criterion were classified as insufficiently physically active 
Table 1 Unweighted sample proportions of central queensland social survey participants by selected sociodemographic and behavioral categories 2002-2008

\begin{tabular}{|c|c|c|c|c|c|c|c|c|}
\hline & $\begin{array}{l}2002 \\
(n=1127)\end{array}$ & $\begin{array}{l}2003 \\
(n=1147)\end{array}$ & $\begin{array}{l}2004 \\
(n=1102)\end{array}$ & $\begin{array}{l}2005 \\
(n=1127)\end{array}$ & $\begin{array}{l}2006 \\
(n=1131)\end{array}$ & $\begin{array}{l}2007 \\
(n=1112)\end{array}$ & $\begin{array}{l}2008 \\
(n=1162)\end{array}$ & $\begin{array}{l}\text { Overall Sample } \\
(n=7908)\end{array}$ \\
\hline \multicolumn{9}{|l|}{ Gender } \\
\hline$\overline{M a l e}$ & 52.1 & 51.9 & 51.1 & 51.6 & 51.5 & 52.0 & 50.9 & 51.6 \\
\hline Female & 47.9 & 48.1 & 48.9 & 48.4 & 48.5 & 48.0 & 49.1 & 48.4 \\
\hline \multicolumn{9}{|l|}{ Age } \\
\hline $18-44$ & 50.8 & 45.5 & 44.7 & 45.6 & 41.6 & 39.3 & 38.8 & 43.8 \\
\hline $45+$ & 49.2 & 54.5 & 55.3 & 54.4 & 58.4 & 60.7 & 61.2 & 56.2 \\
\hline \multicolumn{9}{|l|}{ Employment Status } \\
\hline Yes & 62.3 & 62.8 & 63.7 & 66.5 & 65.8 & 64.6 & 62.8 & 64.1 \\
\hline No & 37.7 & 37.2 & 36.3 & 33.5 & 34.2 & 35.4 & 37.2 & 35.9 \\
\hline \multicolumn{9}{|l|}{ Years of Education } \\
\hline $0-12$ Years & 59.1 & 57.3 & 59.6 & 57.9 & 57.1 & 61.2 & 55.5 & 58.2 \\
\hline $13+$ Years & 40.9 & 42.7 & 40.4 & 42.1 & 42.9 & 38.8 & 44.5 & 41.8 \\
\hline \multicolumn{9}{|l|}{ Smoking Status } \\
\hline$\overline{Y e s}$ & 20.9 & 22.7 & 19.5 & 21.9 & 20.1 & 17.2 & 17.2 & 19.9 \\
\hline No & 79.1 & 77.3 & 80.5 & 78.1 & 79.9 & 82.8 & 82.8 & 80.1 \\
\hline \multicolumn{9}{|l|}{ BMI } \\
\hline Healthy Weight & 42.1 & 43.8 & 44.6 & 40.5 & 37.7 & 37.7 & 37.7 & 40.6 \\
\hline Overweight or Obese & 57.9 & 56.2 & 55.4 & 59.5 & 62.3 & 62.3 & 62.3 & 59.4 \\
\hline \multicolumn{9}{|l|}{ Physical Activity } \\
\hline $\begin{array}{l}\text { Insufficient Physical Activity } \\
\text { (I-MVPA) }\end{array}$ & 56.9 & 53.4 & 54.4 & 53.5 & 51.6 & 60.3 & 46.8 & 53.8 \\
\hline $\begin{array}{l}\text { Sufficient Physical Activity } \\
\text { (S-MVPA) }\end{array}$ & 43.1 & 46.6 & 45.6 & 46.5 & 48.4 & 39.7 & 53.2 & 46.2 \\
\hline \multicolumn{9}{|l|}{ Screen Time } \\
\hline Low Screen Time (LST) & 59.2 & 58.5 & 58.8 & 54.7 & 52.4 & 55.1 & 54.0 & 56.0 \\
\hline High Screen Time (HST) & 40.8 & 41.5 & 42.2 & 45.3 & 47.6 & 44.9 & 46.0 & 44.0 \\
\hline \multicolumn{9}{|l|}{ Combined Behaviors } \\
\hline$\overline{S-M V P A / L S T}$ & 25.7 & 27.6 & 27.0 & 26.7 & 24.9 & 21.5 & 29.4 & 26.1 \\
\hline I-MVPA/LST & 33.5 & 31.0 & 30.9 & 28.0 & 27.5 & 33.6 & 24.6 & 29.8 \\
\hline S-MVPA/HST & 17.4 & 19.0 & 18.6 & 19.8 & 23.4 & 18.2 & 23.8 & 20.0 \\
\hline I-MVPA/HST & 23.4 & 22.5 & 23.6 & 25.5 & 24.1 & 26.7 & 22.2 & 24.0 \\
\hline
\end{tabular}

(I-MVPA). This method of classification is in accordance with previously described methods to reflect compliance with National Physical Activity Guidelines for Australian Adults [2,25,27]. As a marker of leisure time sedentary behavior, TV viewing is more consistently associated with overweight and obesity in females than in males [28-31]. The differences in associations between genders may be because TV viewing is not representative of other leisure time sedentary behaviors in males [32]. Thus, the current study used two measures of screen based activities as indicators of sedentary behavior, TV viewing and computer use, to better represent broader sedentary behaviors of both males and females. Duration of screen based activity reported in hours and minutes was assessed using two separate items, "What do you estimate was the total time that you spent watching TV in the last week?" and "What do you estimate was the total time you spent working in front of a computer screen in the last week?" Data from these two items was summed to provide an overall measure of screen time in the previous week and dichotomized at 21 hours into high screen time (HST) and low screen time (LST) [33]. This classification was selected a priori as it approximates an apparent threshold of screen based activity that is associated with greater risks of ill health compared to lower volumes [14,34]. No psychometric data is available on the items used to assess screen time. Similar to previous research [21], participants were further classified into four mutually exclusive groups to facilitate analyses that combines high and low levels for both physical 
activity and screen time: S-MVPA/LST, I-MVPA/LST, S-MVPA/HST, I-MVPA/HST (these variables are also referred to as 'combined behaviors').

Prior to analysis any duplicate telephone numbers between surveys were excluded. Analysis is delimited to those with complete data for all outcome variables, including screen time, resulting in a different sample size compared to previous analysis of this dataset [5]. Using data pooled from seven cross-sectional surveys (20022008) three separate binary logistic regression models were used to assess associations between the three different behaviors (MVPA, screen time, combined behaviors) and the likelihood to be classified as overweight or obese (Aim 1). To examine temporal trends in the prevalence of overweight or obesity, S-MVPA, and HST over the study period, separate binary logistic regression models were conducted including the ordinal variable, year of survey, as a continuous predictor. Multinomial logistic regression was used to model temporal trends in combined behaviors over the study period using S-MVPA/LST as the reference category and including year of survey as an ordinal variable. This allowed trends over the study period to be examined rather than contrasts between specific years in the study period (Aim 2). For the final analyses, the sample was stratified by each behavior group and separate binary logistic regression models were used to model the trend (year of survey) in overweight or obesity over the study period (Aim 3). All analyses were adjusted for socio-demographic variables listed in table footnotes; all analyses were repeated stratifying the sample by gender due to the significant interaction effect observed in the relationship between overweight or obesity and gender and combined behaviors $(\mathrm{p}<0.05)$.

\section{Results}

The proportion of the overall sample classified as overweight or obese, engaging in S-MVPA and HST as separate behaviors in the pooled sample was $59.4 \%, 46.2 \%$ and $43.1 \%$ respectively. Examination of combined activity behaviors indicates that proportions of the overall sample classified as S-MVPA/LST, I-MVPA/LST, SMVPA/HST, I-MVPA/HST was $26.1 \%, 29.8 \%, 20.0 \%$ and $24.0 \%$ respectively (Table 1 ).

Table 2 displays relationships between engagement in various activity behaviors and the likelihood to be classified as overweight or obese. Engagement in S-MVPA was inversely associated with risk of overweight or obesity in the overall sample (OR=0.85, 95\% CI. 0.78-0.93) and in females (OR=0.76, 95\% CI. 0.67-0.86). Engagement in HST was positively associated with risk of overweight or obesity in the overall sample $(\mathrm{OR}=1.38,95 \%$ CI. 1.26-1.52), males (OR=1.41, 95\% CI. 1.23-1.61) and in females (OR=1.40, 95\% CI. 1.23-1.59). Examination of combined activity behaviors indicates that engagement in HST is positively associated with risk of overweight or obesity regardless of activity classification, and that the magnitude of association was greatest for those in the IMVPA/HST category. This pattern of association was present in the overall sample, males and females (Table 2). Engagement in I-MVPA/LST was significantly associated with risk of overweight or obesity however this was observed only in females.

Table 3 displays that the proportion of the overall population, males and females classified as overweight or obese significantly increased at the same rate over the study period. The proportion of the overall sample and females engaging in S-MVPA (OR=1.03, 95\% CI. 1.011.05; $\mathrm{OR}=1.04,95 \%$ CI. 1.01-1.07) also significantly

Table 2 Associations between physical activity, screen time, combined behavior categories and the likelihood to be classified as overweight or obese

\begin{tabular}{|c|c|c|c|c|c|c|}
\hline & \multicolumn{2}{|c|}{ Overall Sample } & \multicolumn{2}{|c|}{ Males } & \multicolumn{2}{|c|}{ Females } \\
\hline & OR $(95 \% \mathrm{Cl})$ & $\mathrm{p}$ & OR $(95 \% \mathrm{Cl})$ & $\mathrm{p}$ & OR $(95 \% \mathrm{Cl})$ & $\mathrm{p}$ \\
\hline \multicolumn{7}{|l|}{ Physical Activity } \\
\hline Insufficient Physical Activity (I-MVPA) & Reference $^{a}$ & & Reference $^{\mathrm{b}}$ & & Reference $^{c}$ & \\
\hline Sufficient Physical Activity (S-MVPA) & $0.85(0.78-0.93)$ & 0.001 & $0.99(0.87-1.13)$ & 0.852 & $0.76(0.67-0.86)$ & $<0.001$ \\
\hline \multicolumn{7}{|l|}{ Screen Activity } \\
\hline Low Screen Time (LST) & Reference $^{a}$ & & Reference $^{\mathrm{b}}$ & & Reference $^{c}$ & \\
\hline High Screen Time (HST) & $1.38(1.26-1.52)$ & $<0.001$ & $1.41(1.23-1.61)$ & $<0.001$ & $1.40(1.23-1.59)$ & $<0.001$ \\
\hline \multicolumn{7}{|l|}{ Combined Behavior ${ }^{c}$} \\
\hline $\begin{array}{l}\text { S-MVPA/LST } \\
\end{array}$ & Reference $^{a}$ & & Reference $^{\mathrm{b}}$ & & Reference $^{c}$ & \\
\hline I-MVPA/LST & $1.10(0.98-1.24)$ & 0.111 & $0.99(0.84-1.17)$ & 0.912 & $1.20(1.01-1.42)$ & 0.032 \\
\hline S-MVPA/HST & $1.29(1.13-1.47)$ & $<0.001$ & $1.37(1.13-1.66)$ & 0.001 & $1.23(1.02-1.49)$ & 0.028 \\
\hline I-MVPA/HST & $1.62(1.42-1.84)$ & $<0.001$ & $1.42(1.18-1.71)$ & $<0.001$ & $1.83(1.53-2.19)$ & $<0.001$ \\
\hline
\end{tabular}

${ }^{a}$ Adjusted for Gender, Age, Education, Employment Status, Year of Survey, Smoking Status. $\mathrm{n}=7908$.

${ }^{b}$ Adjusted for Age, Education, Employment Status, Year of Survey, Smoking Status. $n=4079$.

c Adjusted for Age, Education, Employment Status, Year of Survey, Smoking Status. $n=3829$. 
Table 3 Trends in overweight and obesity, physical activity, screen time and combined behaviors during the period 2002-2008

\begin{tabular}{|c|c|c|c|c|c|c|}
\hline & \multicolumn{2}{|c|}{ Overall Sample } & \multicolumn{2}{|c|}{ Males } & \multicolumn{2}{|c|}{ Females } \\
\hline & OR $(95 \% \mathrm{Cl})$ & $\mathbf{p}$ & OR $(95 \% \mathrm{Cl})$ & $\mathbf{p}$ & OR $(95 \% \mathrm{Cl})$ & $\mathbf{p}$ \\
\hline \multicolumn{7}{|l|}{ Body Weight } \\
\hline Healthy Weight & Reference $^{a}$ & & Reference $^{d}$ & & Reference $^{f}$ & \\
\hline Overweight or Obese & $1.04(1.02-1.06)$ & 0.001 & $1.04(1.01-1.07)$ & 0.021 & $1.04(1.01-1.07)$ & 0.015 \\
\hline \multicolumn{7}{|l|}{ Physical Activity } \\
\hline Insufficient Physical Activity (I-MVPA) & Reference $^{\mathrm{b}}$ & & Reference $^{\mathrm{e}}$ & & Reference $^{\text {h }}$ & \\
\hline Sufficient Physical Activity (S-MVPA) & $1.03(1.01-1.05)$ & 0.010 & $1.02(0.99-1.05)$ & 0.211 & $1.04(1.01-1.07)$ & 0.013 \\
\hline \multicolumn{7}{|l|}{ Screen Activity } \\
\hline Low Screen Time (LST) & Reference $^{\mathrm{b}}$ & & Reference $^{e}$ & & Reference $^{h}$ & \\
\hline High Screen Time (HST) & $1.03(1.01-1.06)$ & 0.004 & $1.04(1.01-1.08)$ & 0.009 & $1.03(1.00-1.07)$ & 0.049 \\
\hline \multicolumn{7}{|l|}{ Combined Behavior } \\
\hline S-MVPA/LST & Reference $^{c}$ & & Reference $^{g}$ & & Reference $^{i}$ & \\
\hline I-MVPA/LST & $0.97(0.94-0.99)$ & 0.019 & $0.98(0.94-1.02)$ & 0.327 & $0.95(0.92-0.99)$ & 0.019 \\
\hline S-MVPA/HST & $1.03(1.00-1.06)$ & 0.098 & $1.04(1.00-1.09)$ & 0.073 & $1.02(0.98-1.07)$ & 0.348 \\
\hline I-MVPA/HST & $1.00(0.97-1.04)$ & 0.782 & $1.02(0.98-1.07)$ & 0.334 & $0.99(0.95-1.04)$ & 0.763 \\
\hline \multicolumn{7}{|c|}{$\begin{array}{l}\text { a Adjusted for Gender, Age, Education, Employment Status, Physical Activity, Smoking Status \& Screen Time. n=7908. } \\
\text { b Adjusted for Gender, Age, Education, Employment Status, \& Smoking Status. n=7908. } \\
\text { c Adjusted for Gender, Age, Education, Employment Status, \& Smoking Status. } n=7908 \text {. } \\
\text { d Adjusted for Age, Education, Employment Status, Smoking Status, Physical Activity, \& Screen Time. } n=4079 . \\
\text { e Adjusted for Age, Education, Employment Status, Smoking Status. } n=4079 \text {. } \\
\text { f Adjusted for Age, Education, Employment Status, Smoking Status, Physical Activity, \& Screen Time. n=3829. } \\
\text { g Reference Category is all other behavior categories. Adjusted for Age, Education, Employment Status, Smoking Status. n=4079. } \\
\text { h Adjusted for Age, Education, Employment Status, Smoking Status. n=3829. } \\
\text { ' Reference Category is all other behavior categories. Adjusted for Age, Education, Employment Status, Smoking Status. n=3829. }\end{array}$} \\
\hline
\end{tabular}

increased. The proportion of the overall sample, males and females engaging in HST increased significantly over the study period $(\mathrm{OR}=1.03,95 \%$ CI. 1.01-1.06; $\mathrm{OR}=1.04$, 95\% CI.1.01-1.08; OR=1.03, 95\% CI. 1.00-1.07). The proportion of the overall and female population classified as I-MVPA/LST declined over the study period (Table 3). Figure 1 displays the change in the proportion of the overall population classified as overweight and obese, SMVPA/LST, I-MVPA/LST, S-MVPA/HST and S-MVPA/ LST by year of survey.

Table 4 displays changes in the prevalence of overweight or obesity within each behavior category during the study period. Tests of interaction effects between each behaviour category and year of survey were not statistically significant for any of the outcomes presented in Table $4(\mathrm{p}>0.05)$. In the overall sample the prevalence of overweight or obesity significantly increased in those people classified as engaging in I-MVPA and S-MVPA $(\mathrm{OR}=1.05$, 95\% CI. 1.02-1.08; OR $=1.04$, 95\% CI. 1.001.07), LST and HST (OR=1.03, 95\% CI. 1.00-1.06; $\mathrm{OR}=1.05, \quad 95 \% \quad$ CI. 1.02-1.09) and I-MVPA/HST $(\mathrm{OR}=1.06,95 \%$ CI. 1.01-1.11). In males the prevalence of overweight and obesity significantly increased in those classified as engaging in S-MVPA (OR=1.06, 95\% CI. 1.01-1.10) and LST (OR=1.04, 95\% CI. 1.00-1.09). The prevalence of overweight or obesity significantly increased in those females classified as engaging in I-
MVPA (OR=1.07, 95\% CI. 1.02-1.11), HST $(\mathrm{OR}=1.07$, 95\% CI. 1.02-1.12) and I-MVPA/HST (OR=1.10, 95\% CI. 1.03-1.17).

\section{Discussion}

This study examined relationships between physical activity, screen time, the combination of these behaviors and the likelihood to be classified as overweight or obese and also temporal trends in these outcomes during the period 2002-2008. In the overall sample and in females, engagement in S-MVPA was associated with a reduced likelihood to be classified as overweight or obese, while engagement in HST was associated with an increased likelihood to be classified as overweight or obese irrespective of activity level measured by the Active Australia Questionnaire. This pattern of associations is consistent with previous research that examined similar behavioral and health outcomes $[14,21]$. In males, with the exception of participation in S-MVPA, associations between screen time and combined behaviors and the likelihood to be classified as overweight or obese followed expected patterns [16,31]. The lack of association between S-MVPA and overweight or obesity in males in the current study is both in agreement $[35,36]$, and in contrast to previous studies $[37,38]$, and may be attributed to an positive energy imbalance, caused by energy intake exceeding energy expenditure 


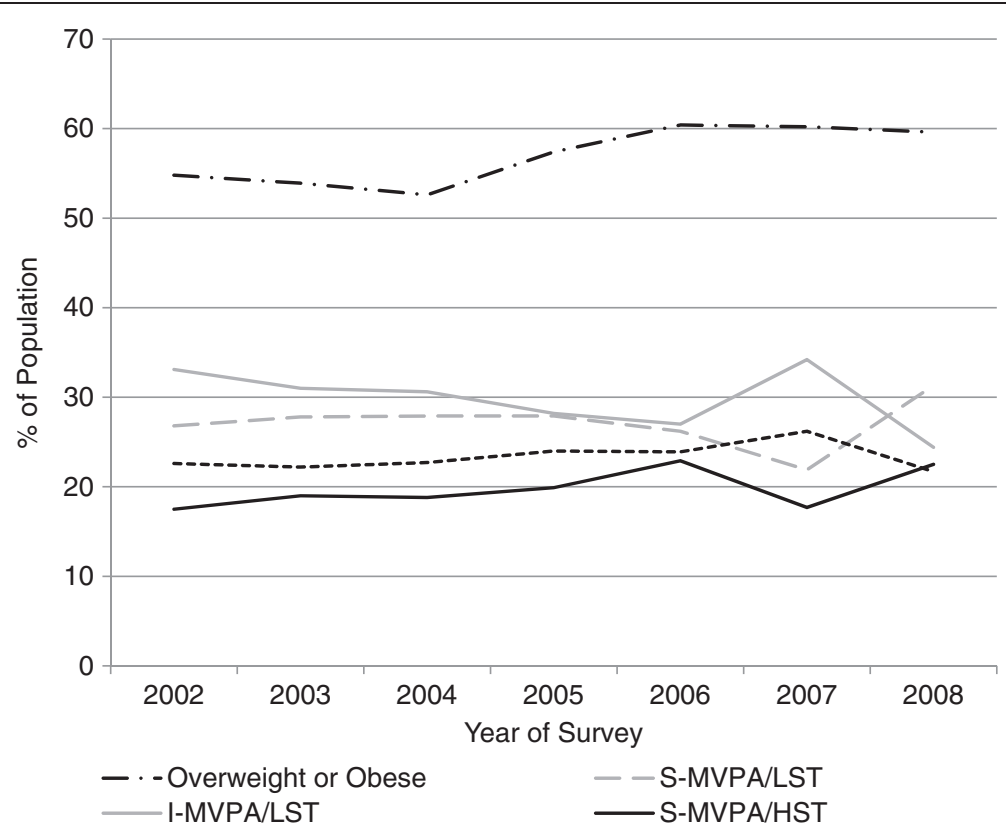

Figure 1 Trends in the prevalence of overweight and obesity and combined behaviors during the period 2002-2008.

even when males engage in S-MVPA $[7,11]$. The current study does not include a measure of energy intake which limits the ability to examine this mechanism.

While TV viewing is more broadly reflective of females sedentary activity than males, we attempted to offset this in the current study by incorporating a measure of computer use which is an activity that contributes more to males overall sedentary time than females [32]. Despite this, in females, associations between MVPA, screen behaviors and overweight or obesity were observed in all categories of combined behavior (I-MVPA/LST; SMVPA/HST; I-MVPA/HST) whilst in males, associations between combined behavior and overweight or obesity were observed for selected behaviors (S-MVPA/HST; I-MVPA/HST). Several potential mechanisms may be attributed to this. The screen time and physical activity measures used in this study may better capture overall energy expenditure in females compared to males. Alternatively differences in dietary patterns may also contribute to the differing associations observed. Thus future studies should consider using measures of physical activity and sedentary behavior that capture activity in all domains and incorporate a measure of energy intake or dietary quality. Withstanding these comments, the increased risk of

Table 4 Trends in overweight and obesity within behavior categories during the period 2002-2008

\begin{tabular}{|c|c|c|c|c|c|c|c|c|c|}
\hline & \multicolumn{9}{|c|}{ Trend for Overweight \& Obese within Behavior Categories } \\
\hline & \multicolumn{3}{|c|}{ Overall Sample } & \multicolumn{3}{|c|}{ Males } & \multicolumn{3}{|c|}{ Females } \\
\hline & $\mathrm{n}$ & OR $(95 \% \mathrm{Cl})$ & $\mathbf{p}$ & $\mathrm{n}$ & OR $(95 \% \mathrm{Cl})$ & $\mathbf{p}$ & n & OR $(95 \% \mathrm{Cl})$ & $\mathbf{p}$ \\
\hline \multicolumn{10}{|l|}{ Physical Activity } \\
\hline Insufficient Physical Activity (I-MVPA) & 4256 & $1.05(1.02-1.08)^{\mathrm{a}}$ & 0.002 & 2173 & $1.03(0.99-1.08)^{b}$ & 0.154 & 2083 & $1.07(1.02-1.11)^{b}$ & 0.007 \\
\hline Sufficient Physical Activity (S-MVPA) & 3652 & $1.04(1.00-1.07)^{\mathrm{a}}$ & 0.039 & 1906 & $1.05(1.00-1.10)^{b}$ & 0.032 & 1746 & $1.02(0.97-1.06)^{b}$ & 0.319 \\
\hline \multicolumn{10}{|l|}{ Screen Activity } \\
\hline Low Screen Time (LST) & 4426 & $1.03(1.00-1.06)^{\mathrm{a}}$ & 0.049 & 2260 & $1.04(1.00-1.09)^{\mathrm{b}}$ & 0.043 & 2166 & $1.01(0.97-1.06)^{b}$ & 0.517 \\
\hline High Screen Time (HST) & 3482 & $1.05(1.02-1.09)^{a}$ & 0.005 & 1819 & $1.03(0.98-1.09)^{b}$ & 0.232 & 1663 & $1.07(1.02-1.12)^{b}$ & 0.008 \\
\hline \multicolumn{10}{|l|}{ Combined Behavior } \\
\hline S-MVPA/LST & 2067 & $1.02(0.98-1.07)^{a}$ & 0.264 & 1057 & $1.05(0.98-1.11)^{b}$ & 0.156 & 1010 & $1.00(0.94-1.06)^{b}$ & 0.957 \\
\hline I-MVPA/LST & 2359 & $1.04(1.00-1.08)^{\mathrm{a}}$ & 0.070 & 1203 & $1.05(0.99-1.11)^{b}$ & 0.131 & 1156 & $1.03(0.97-1.09)^{b}$ & 0.302 \\
\hline S-MVPA/HST & 1585 & $1.05(0.99-1.10)^{\mathrm{a}}$ & 0.089 & 849 & $1.06(0.98-1.14)^{b}$ & 0.127 & 736 & $1.03(0.96-1.11)^{b}$ & 0.354 \\
\hline I-MVPA/HST & 1897 & $1.06(1.01-1.11)^{a}$ & 0.021 & 970 & $1.01(0.94-1.08)^{b}$ & 0.891 & 927 & $1.10(1.03-1.17)^{b}$ & 0.005 \\
\hline
\end{tabular}

${ }^{a}$ Adjusted for Gender, Age, Education, Employment Status \& Smoking Status.

${ }^{\mathrm{b}}$ Adjusted for Age, Education, Employment Status \& Smoking Status. 
overweight or obesity in individuals who engaged in HST (irrespective of measured MVPA) highlights the need for interventions to target reductions in sedentary activities and increases in light, moderate and vigorous intensity physical activity to maximize overall increases in energy expenditure to reduce the risk of overweight or obesity. Increasing light intensity physical activity may be important as it is likely that this is the behavior engaged in when sitting time is reduced [39] and increased light intensity physical activity is associated with improved metabolic health [40].

Several studies have reported that the proportion of the population engaging in S-MVPA has remained stable or increased in Australian populations [4], including this population [5], and populations from other countries $[3,41]$. As such the more unique aspect of this study, withstanding variations between individual years examined (Table 1), is that it demonstrates that in the overall population and in females, the proportion of the population classified as overweight or obese has increased over the same time period and at a similar rate to the increased proportion of the population engaging in sufficient MVPA and high screen time. Similar patterns of change were observed in males however the change in the prevalence of S-MVPA over the study period was not statistically significant. Therefore the promising changes in the prevalence of sufficient MVPA should be viewed with cautious optimism. As it appears that some segments of the population have responded to recent efforts to promote engagement in MVPA, and at the same time also appear to spend increasing amounts of time in sedentary activities. Still, these data provide much needed information on the trends of these multiple behaviors at a population level.

The proportion of the population classified as overweight or obese increased in most physical activity and screen time groups when examined as separate behavior groups, and significantly increased only in the I-MVPA/ HST group (overall sample and females) when combined behavior groups were examined. Furthermore, the rate of change in the combined activity group was marginally larger than observed when separate behavior groups were examined, although this was not significant in males. Although these conclusions must be interpreted with caution as the data are not longitudinal, and there are inconsistent data surrounding the associations between screen time and weight status compared to weight gain $[15,42]$.

Although interesting, findings in the current study are subject to several limitations, including the use of selfreport measures of MVPA, screen time and BMI. Selfreported BMI although practical in population based studies such as the current study has well acknowledged limitations [43] therefore future studies are encouraged to use objective measures of body composition to confirm the pattern of results observed in the current study. Also the measures of screen time used may be not representative of the broader time spent in sedentary activities [32]. Other limitations include the absence of longitudinal data, a lack of data on actual sedentary behavior and reliance on proxy measures of these behaviors, the absence of a measure of sedentary activity in transport related activities and the absence of a measure of energy intake. Strengths of the study are the use of consistent methodology and survey instruments over the study period and the study sample size. The sample size of the study meant that even relatively small shifts in the population prevalence of behaviors, overweight and obesity over the study period were statistically significant. However, the results do highlight important changes in behaviors at the population level.

\section{Conclusions}

The findings of this study support previous observations that high levels of time spent engaged in screen based activity is associated with overweight or obesity in cross sectional analyses, even when MVPA is considered $[16,21]$. It was also observed that the prevalence of overweight or obesity appears to have increased at a similar magnitude to the prevalence of the population that engage in sufficient MVPA and high levels of screen time. Finally, we found that in the overall sample and females, the prevalence of overweight or obesity increased over time only in those who participated in insufficient levels of MVPA and high levels of screen time. Greater understanding of these relationships and trends over time requires measures of actual sedentary behaviors, such as sitting, that accurately capture the behaviors of both males and females and examination of these behaviors in both population and cohort based samples.

\section{Competing interests}

The author declare that they have no competing interests.

\section{Authors' contributions}

MJD proposed the study concept, conducted statistical analyses and drafted the original manuscript. CH assisted in statistical analyses. CC, CV and WKM provided important intellectual feedback and critique of the study concept and approach. All authors contributed to the drafting and editing of the manuscript and approved the final manuscript.

\section{Acknowledgements}

The authors would like to thank the staff of the Population Research Laboratory, CQUniversity and participants who have taken part in the CQSS during the study period. Vandelanotte is supported by a National Health and Medical Research Council of Australia (\#519778) and National Heart Foundation of Australia (\#PH 07B 3303) post-doctoral research fellowship. The Central Queensland Social Survey is an annual omnibus survey funded by the Institute for Health and Social Science Research (IHSSR) and is conducted by the Population Research Laboratory at CQUniversity Australia.

\section{Author details}

${ }^{1}$ CQUniversity, Institute for Health and Social Science Research, Centre for Physical Activity Studies, Rockhampton, Bld 18, CQUniversity Australia, 
Rockhampton, QLD 4702, Australia. ${ }^{2}$ Faculty of Health and Social Development, University of British Columbia, Kelowna, Canada. ${ }^{3}$ Faculty of

Physical Education and Recreation, University of Alberta, Edmonton, Canada.

Received: 26 January 2012 Accepted: 30 November 2012

Published: 8 December 2012

\section{References}

1. Bauman AE: Updating the evidence that physical activity is good for health: an epidemiological review 2000-2003. J Sci Med Sport 2004, 7(1 Suppl):6-19.

2. Brown W, Bauman A, Chey T, Trost S, Mummery K: Comparison of surveys used to measure physical activity. Aust N Z J Public Health 2004, 28(2):128-134

3. Brownson RC, Boehmer TK, Luke DA: Declining rates of physical activity in the United States: what are the contributors? Annu Rev Public Health 2005, 26:421-443.

4. Chau J, Smith BJ, Bauman A, Merom D, Eyeson-Annan M, Chey T, Farrell L: Recent trends in physical activity in New South Wales. Is the tide of inactivity turning? Aust N Z J Public Health 2008, 32 (1):82-85

5. Vandelanotte C, Duncan MJ, Caperchione C, Hanley C, Mummery WK: Physical activity trends in Queensland (2002 to 2008): are women becoming more active than men? Aust N Z J Public Health 2010, 34(3):248-254

6. Knuth AG, Hallal PC: Temporal trends in physical activity: a systematic review. J Phys Act Health 2009, 6(5):548-559.

7. Bauman A, Allman-Farinelli M, Huxley $R$, James WP: Leisure-time physical activity alone may not be a sufficient public health approach to prevent obesity-a focus on China. Obes Rev 2008, 9(Suppl 1):119-126.

8. Australian Bureau of Statistics: Australian Social Trends 2007. Australian Bureau of Statistics: Overweight and obesity. In. Canberra; 2007.

9. Flegal KM, Carroll MD, Ogden CL, Curtin LR: Prevalence and trends in obesity among US adults, 1999-2008. JAMA, 303(3):235-241

10. Stamatakis $E$, Ekelund U, Wareham NJ: Temporal trends in physical activity in England: the Health Survey for England 1991 to 2004. Prev Med 2007, 45(6):416-423.

11. Hill JO, Wyatt HR, Reed GW, Peters JC: Obesity and the environment: where do we go from here? Science 2003, 299(5608):853-855.

12. Pate RR, O'Neill JR, Lobelo F: The evolving definition of "sedentary". Exerc Sport Sci Rev 2008, 36(4):173-178.

13. Clark BK, Sugiyama T, Healy GN, Salmon J, Dunstan DW, Owen N: Validity and reliability of measures of television viewing time and other non-occupational sedentary behaviour of adults: a review. Obes Rev 2009, 10(1):7-16.

14. Hu FB, Leitzmann MF, Stampfer MJ, Colditz GA, Willett WC, Rimm EB: Physical activity and television watching in relation to risk for type 2 diabetes mellitus in men. Arch Intern Med 2001, 161(12):1542-1548.

15. Hu FB, Li TY, Colditz GA, Willett WC, Manson JE: Television watching and other sedentary behaviors in relation to risk of obesity and type 2 diabetes mellitus in women. JAMA 2003, 289(14):1785-1791.

16. Vandelanotte C, Sugiyama T, Gardiner P, Owen N: Associations of leisure-time internet and computer use with overweight and obesity, physical activity and sedentary behaviors: cross-sectional study. $J$ Med Internet Res 2009, 11(3):e28.

17. Owen N, Bauman A, Brown W: Too Much Sitting. Br J Sports Med: A Novel and Important Predictor of Chronic Disease Risk? 2008.

18. Hamilton MT, Healy GN, Dunstan DW, Zderic TW, Owen N: Too little exercise and too much sitting: inactivity physiology and the need for new recommendations on sedentary behavior. Current Cardiovascular Risk Reports 2008, 2(4):292-298.

19. Church TS, Thomas DM, Tudor-Locke C, Katzmarzyk PT, Earnest CP, Rodarte RQ, Martin CK, Blair SN, Bouchard C: Trends over 5 decades in U.S. Occupation-related physical activity and their associations with obesity. PLoS One 2011, 6(5):19657.

20. Chau JY, Merom D, Grunseit A, Rissel C, Bauman AE, van der Ploeg HP: Temporal trends in non-occupational sedentary behaviours from Australian Time Use Surveys 1992, 1997 and 2006. International Journal of Behavioral Nutrition and Physical Activity 2012, 9(1):76
21. Sugiyama T, Healy GN, Dunstan DW, Salmon J, Owen N: Joint associations of multiple leisure-time sedentary behaviours and physical activity with obesity in Australian adults. Int I Behav Nutr Phys Act 2008, 5:35.

22. Ainsworth BE, Wilcox S, Thompson WW, Richter DL, Henderson KA: Personal, social, and physical environmental correlates of physical activity in African-American women in South Carolina. Am J Prev Med 2003, 25(3 Suppl 1):23-29.

23. Badland HM, Schofield GM: Health Associations with Transport-Related Physical Activity and Motorized Travel to Destinations. Int I Sustainable Transportation 2008, 2(2):77-90.

24. Australian Institute of Health and Welfare: The active Australia survey: A guide and manual for implementation, analysis and reporting. Canberra: AlHW; 2003.

25. Brown WJ, Bauman A, Trost S, Mummery WK, Owen N: Test-retest reliability of four physical activity measures used in population surveys. Journal of Science and Medicine in Sport 2004, 7(2):205-215.

26. Timperio A, Salmon J, Bull F, Rosenburg M: Validation of adult physical activity questions for use in Australia population surveys. Canberra: Department of Health and Ageing; 2002. unpublished report.

27. Department of Health and Aged Care: National physical activity guidelines for Australians. Canberra: DHAC; 1999.

28. Dunstan DW, Salmon J, Owen N, Armstrong T, Zimmet PZ, Welborn TA, Cameron AJ, Dwyer T, Jolley D, Shaw JE: Physical activity and television viewing in relation to risk of undiagnosed abnormal glucose metabolism in adults. Diabetes Care 2004, 27(11):2603-2609.

29. Dunstan DW, Salmon J, Healy GN, Shaw JE, Jolley D, Zimmet PZ, Owen N: Association of television viewing with fasting and 2-h postchallenge plasma glucose levels in adults without diagnosed diabetes. Diabetes Care 2007, 30(3):516-522.

30. Bertrais S, Beyeme-Ondoua JP, Czernichow S, Galan P, Hercberg S, Oppert JM: Sedentary behaviors, physical activity, and metabolic syndrome in middle-aged French subjects. Obes Res 2005, 13 (5):936-944

31. Dunstan DW, Salmon J, Owen N, Armstrong T, Zimmet PZ, Welborn TA, Cameron AJ, Dwyer T, Jolley D, Shaw JE: Associations of TV viewing and physical activity with the metabolic syndrome in Australian adults. Diabetologia 2005, 48(11):2254-2261.

32. Sugiyama T, Healy GN, Dunstan DW, Salmon J, Owen N: Is television viewing time a marker of a broader pattern of sedentary behavior? Ann Behav Med 2008, 35(2):245-250

33. Davies CA, Vandelanotte C, Duncan MJ, van Uffelen JG: Associations of physical activity and screen-time on health related quality of life in adults. Prev Med 2012, 55(1):46-49.

34. Banks E, Jorm L, Rogers K, Clements M, Bauman A: Screen-time, obesity, ageing and disability: findings from 91266 participants in the 45 and Up Study. Public Health Nutr 2011, 14(1):34-43.

35. Rainwater DL, Mitchell BD, Comuzzie AG, VandeBerg JL, Stern MP, MacCluer JW: Association among 5-year changes in weight, physical activity, and cardiovascular disease risk factors in Mexican Americans. Am J Epidemio 2000, 152(10):974-982

36. Seo DC, Li K: Leisure-time physical activity dose-response effects on obesity among US adults: results from the 1999-2006 National Health and Nutrition Examination Survey. J Epidemiol Community Health 2010, 64(5):426-431

37. Salmon J, Bauman A, Crawford D, Timperio A, Owen N: The association between television viewing and overweight among Australian adults participating in varying levels of leisure-time physical activity. Int J Obes Relat Metab Disord 2000, 24(5):600-606.

38. Lahti-Koski M, Pietinen P, Heliovaara M, Vartiainen E: Associations of body mass index and obesity with physical activity, food choices, alcohol intake, and smoking in the 1982-1997 FINRISK Studies. Am J Clin Nutr 2002, 75(5):809-817.

39. Owen N, Healy GN, Matthews CE, Dunstan DW: Too much sitting: the population-health science of sedentary behavior. Exercise and sport sciences reviews 2010, 38(3):105.

40. Healy GN, Dunstan DW, Salmon J, Cerin E, Shaw JE, Zimmet PZ, Owen $\mathrm{N}$ : Objectively measured light-intensity physical activity is independently associated with 2 -h plasma glucose. Diabetes Care 2007, 30(6):1384-1389.

41. Juneau CE, Potvin L: Trends in leisure-, transport-, and work-related physical activity in Canada 1994-2005. Prev Med 2010, 51(5):384-386 
42. Van Uffelen JG, Watson MJ, Dobson AJ, Brown WJ: Sitting time is associated with weight, but not with weight gain in mid-aged Australian women. Obesity (Silver Spring) 2010, 18(9):1788-1794.

43. Strommel M, Schoenborn CA: Accuracy and usefulness of BMI measures based on selfreported weight and height: findings from the NHANES \& NHIS 2001-2006. BMC Public Health 2009, 9:421.

doi:10.1186/1471-2458-12-1060

Cite this article as: Duncan et al:: Temporal trends in and relationships between screen time, physical activity, overweight and obesity. BMC

Public Health 2012 12:1060

\section{Submit your next manuscript to BioMed Central and take full advantage of:}

- Convenient online submission

- Thorough peer review

- No space constraints or color figure charges

- Immediate publication on acceptance

- Inclusion in PubMed, CAS, Scopus and Google Scholar

- Research which is freely available for redistribution 